\title{
Modeling of Noise Power Spectral Density Analysis for GaN/AlGaN HEMT
}

\author{
Palanichamy Vimala, L. Vidyashree \\ Department of Electronics and Communication Engineering, Dayananda Sagar College of Engineering, Bangalore, India \\ Email:ervimala@gmail.com, vidyashree155@gmail.com
}

How to cite this paper: Vimala, P. and Vidyashree, L. (2016) Modeling of Noise Power Spectral Density Analysis for GaN/ AlGaN HEMT. Journal of Applied Mathematics and Physics, 4, 1906-1915. http://dx.doi.org/10.4236/jamp.2016.410193

Received: July 18, 2016

Accepted: October 22, 2016

Published: October 25, 2016

Copyright $\odot 2016$ by authors and Scientific Research Publishing Inc. This work is licensed under the Creative Commons Attribution International License (CC BY 4.0).

http://creativecommons.org/licenses/by/4.0/

\begin{abstract}
Nano Technology is the branch of technology that deals with dimensions and tolerances in terms of nanometers. In this paper, the electrical characteristics analysis is determined for the Nano-GaN HEMT and Micro-GaN HEMT and also power spectrum density is determined for GaN Nano-HEMT by reducing the gate length $\mathrm{Lg}$ in $\mathrm{nm}$ range. The GaN Nano HEMT is producing high current comparing to Micro GaN HEMT. Accuracy of the proposed analytical model results is verified with simulation results.
\end{abstract}

\section{Keywords}

HEMT, GaN/AlGaN, 2DEG, Drain Current, Noise Power Spectrum Density

\section{Introduction}

High electron mobility transistors are made up of the GaAs semiconductor material, but the research on HEMT experts says that GaN has good characteristics than GaAs because of their good breakdown voltage, less power dissipation. It can operate at high temperature, and it is having more power density and can operate at high voltage compared to GaAs based HEMT for that purpose. We are talking about GaN/AlGaN HEMT here [1]-[3].

The Applications of GaN/AlGaN HEMT are used in Space applications, Radar and in satellites because they are considered to be very promising candidates for high-speed and high-power applications. These devices offer advantages such as high breakdown voltage, high charge density, and good electron mobility [1]. The formation of the 2dimensional electron gas (2DEG) in these devices is the heart of the device operation and has been studied in great detail in the literature [4]-[6]. Many articles are present for HEMTs, but the dimension used for gate length is in micrometer range [7]-[9]. Thus, there is scope for developing a simple accurate analytical model for GaN HEMT 
by considering the gate length dimension in nanometer range $(100 \mathrm{~nm})$.

In this paper, we developed electrical characteristics analytical model for the GaN/AlGaN HEMT. Using the dimensions and the parameters of developed HEMT, we have compared the I-V characteristics for the Nano meter gate length and Micro meter gate length GaN-HEMT, and we have determined the noise power spectrum density for Nano GaN HEMT using Matlab and the performance is compared with the simulation results.

\section{Model Formation}

We call High electron mobility transistor as a Heterostructure FET because it uses two different semiconductor materials. One semiconductor should have a higher energy band gap and another one should have a lower energy band gap for the conduction takes place. We also call it as a MODFET (Modulation doping FET) he term "modulation doping" refers to the fact that the dopants are spatially in a different region from the current carrying electrons.

The schematic cross-section of the AlGaN/GaN HEMT is shown in Figure 1(a). GaN-based HEMTs employ two kinds of materials with different band gaps as the barrier and channel layer. The most popular one is AlGaN/GaN HEMTs. Due to the conduction band offset between $\mathrm{AlGaN}$ and $\mathrm{GaN}$, an electron potential quantum well is formed at the hetero-interface between AlGaN and GaN. This heterojunction of different band-gap materials constitutes a triangular-like quantum well on the GaN side of the conduction band which allows electrons move freely parallel to the heterojunction plane without any impurity collision. This collection of high mobility electrons inside the quantum well is called two-dimensional electron gas (2DEG).

Figure 1(b) shows the 2DEG produced between GaN and AlGaN semiconductor materials. Fermi level of both the bands must be equal for the conduction takes place. This is known as the equilibrium state. When we give the gate voltage, the conduction band of AlGaN raises to communicate with the GaN conduction band and the conduction band of $\mathrm{GaN}$ material bends down to communicate with AlGaN material in between these two we will get the 2DEG it is like a channel in MOSFET where the electrons

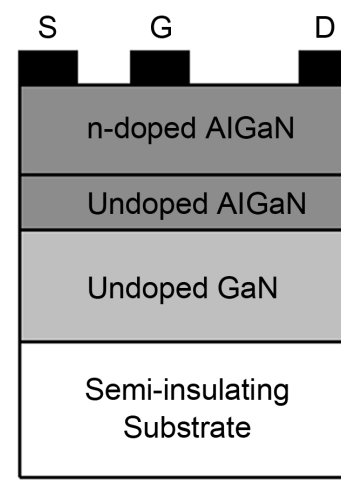

(a)

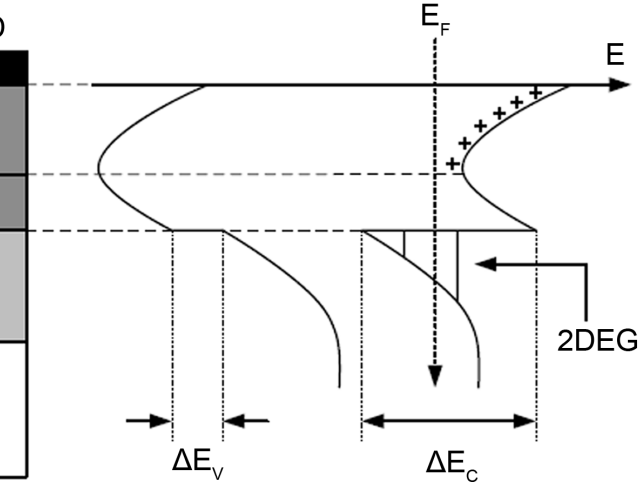

(b)

Figure 1. (a) Cross section and (b) band diagram of GaN HEMT structure. 
are present and they start moving for the applied gate voltage and drain voltage. The electrons are confined in this potential well to form a 2DEG. The electrons transport in a two-dimensional way, which can largely improve the electron mobility.

Table 1 shows the properties of different semiconductor materials. We can see GaN semiconductor material has a good property compared to the $\mathrm{Si}, \mathrm{GaAs}$ and SIC semiconductor materials. Hence we are discussing about GaN HEMT here.

\section{Drain Current Characteristics and Noise Power Spectrum Densities of GaN HEMT}

\section{1. $I_{d}$ Characteristics of GaN HEMT}

If assumed a constant mobility, then for low values of $V_{d s}$ (drain to source voltage), the drain current $I_{d}$ in the linear region is given by [10],

$$
I_{d}=\varepsilon_{N} \mu \frac{\omega}{2 L(d+\Delta d)}\left[2\left(V_{g s}-V_{\text {off }}\right) V_{d s}-V_{d s}^{2}\right], \text { for } V_{d s} \leq V_{g s}-V_{\text {off }}
$$

$V_{d s}$ is further increased, then the carrier reaches the saturation voltage and the saturated drain current Drain current becomes,

$$
I_{d}=\varepsilon_{N} \mu \frac{\omega}{2 L(d+\Delta d)}\left(V_{g s}-V_{\text {off }}\right)^{2}, \text { for } V_{d s} \geq V_{g s}-V_{\text {off }}
$$

where,

$\varepsilon_{N}$-permittivity of the substrate material in HEMT;

$V_{g s}$-The gate to source voltage;

$V_{\text {off }}$-Offset voltage.

The offset voltage $V_{\text {off }}$ can be calculated by the formula [10],

$$
V_{\text {off }}=\phi_{B}-\frac{\Delta E_{C}}{q}-V_{P 2}
$$

$V_{p 2}$ can be calculated by using formula [10],

$$
V_{p 2}=\frac{q N_{d d}^{2}}{2 \varepsilon_{N}}
$$

\begin{tabular}{|c|c|c|c|c|c|}
\hline \multirow[b]{2}{*}{ Property } & \multicolumn{5}{|c|}{ Material } \\
\hline & $\begin{array}{c}\mathrm{GaN} \\
\mathrm{AlGaN} / \mathrm{GaN}\end{array}$ & $\mathrm{SiC}$ & Diamond & $\mathrm{Si}$ & $\begin{array}{c}\text { GaAs/AlGaAs } \\
\text { InGaAs }\end{array}$ \\
\hline Band gap energy, Eg (MV/cm) & $3.44 \mathrm{eV}$ & $3.26 \mathrm{eV}$ & $5.45 \mathrm{eV}$ & $1.12 \mathrm{eV}$ & $1.43 \mathrm{eV}$ \\
\hline Electric breakdown field, Ec $(\mathrm{MV} / \mathrm{cm})$ & 3 & 3 & 10 & 0.3 & 0.4 \\
\hline $\begin{array}{l}\text { Saturated (Peak) Velocity electronics, Vsat (VPeak) } \\
\qquad\left(\times 10^{7} \mathrm{~cm} / \mathrm{s}\right)\end{array}$ & 2.5 & 2.0 & 2.7 & 1.0 & 1.0 \\
\hline Electron mobility, $\mu_{s}\left(\mathrm{~cm}^{2} / \mathrm{V} \cdot \mathrm{s}\right)$ & 900 & 700 & 4800 & 1500 & 8500 \\
\hline 2DEG density, $n_{s}\left(\times 10^{13} \mathrm{~cm}^{-2}\right)$ & 1.0 & N.A & N.A & N.A & $<0.2$ \\
\hline Thermal conductivity $(\mathrm{W} / \mathrm{cm} \cdot \mathrm{K})$ & $1.3-2.1$ & $3.7-4.5$ & 22 & 1.5 & 0.5 \\
\hline Relative Permittivity $\varepsilon_{r}$ & 9.0 & 10.1 & 5.5 & 11.8 & 1.8 \\
\hline
\end{tabular}

Table 1. Material properties of semiconductors at $300 \mathrm{~K}$. 


\subsection{Noise Power Spectrum Densities}

Noise power spectral densities (PSD) can be described as superposition of flicker noise, thermal noise and several generation-recombination (G-R) noise components.

- (G-R) Noise: The temperature dependence of the (G-R) noise arising from the traps was used to deduce the thermal activation energies and cross sections. The present results are compared to those of the literature to identify the Physica-chemical nature of traps responsible of the G-R noise.

- Flicker Noise: Flicker noise is found in all active devices as well as passive elements. Flicker noise dominates noise at low frequencies. The noise spectral density has a $1 / \mathrm{f}$ frequency dependence and hence the name " $1 / \mathrm{f}$ " noise. This noise source is most significant at low frequencies, although in devices exhibiting high flicker noise.

- Thermal noise: This is directly proportional to the absolute temperature (T) and as $\mathrm{T}$ approaches zero, the thermal noise also approaches zero. The thermal noise spectral density is also independent of the frequency and thus thermal noise can also classified as white noise.

The Noise power spectrum Density analysis of Nano-HEMT using GaN material can obtain by drain current. After obtaining the drain current of GaN Nano-HEMT and GaN Micro-HEMT, the noise PSD can be calculated by following the Hooge's expression [11].

$$
S_{i d}=\frac{I_{d}^{2} \alpha_{H}}{f^{N}}
$$

where,

$S_{i d}=$ Noise power spectrum density;

$I_{d}=$ Drain current;

$f$ = operating frequency;

$N=$ Total no of electrons in the conduction Band;

$\alpha_{H}=$ Hooge's parameter of GaN.

Hooge's Parameter is the dimensionless parameter. Very recently, a mobility fluctuation noise theory was proposed by Musha and Tacano, suggests that energy partition among weakly coupled harmonic oscillators in an equilibrium system is subjected to $1 / \mathrm{f}$ fluctuations.

\section{Results and Discussion}

The accuracy of the proposed model is validated using the commercially available TCAD Sentaurus device simulator. The set of parameters used for simulation are shown in Table 2 .

The Drain current characteristics plotted for GaN HEMT for $\mathrm{Lg}$ in 1 micrometer is shown in Figure 2 and for $\mathrm{Lg}$ in 100 nanometer is shown in Figure 3. From the figures it is observed that um gate length GaN HEMT produces less Drain current compared to the Nano GaN HEMT. The Drain current of GaN Nano-HEMT is hundred times more than that of GaN HEMT is observed in Figure 2 and Figure 3. 
Table 2. List of parameters used in equations and their values that are used to obtain results.

\begin{tabular}{|c|c|c|}
\hline Symbol & Description & Value/unit \\
\hline$W$ & Gate width & $1 \mu \mathrm{m}$ \\
\hline$L$ & Gate Length & $100 \mathrm{~nm}$ \\
\hline$N_{d}$ & Donor level concentration & $1 \times 10^{19} \mathrm{~cm}^{-3}$ \\
\hline$K$ & Boltzmann's Constant & $1.38 \times 10^{-23} \mathrm{~J} / \mathrm{K}$ \\
\hline$T$ & Operating temperature & $300 \mathrm{~K}$ \\
\hline$Q$ & Electronic charge & $1.6 \times 10^{-19} \mathrm{C}$ \\
\hline$D_{d}$ & Thickness of doped layer in Nano-HEMT & $90 \mathrm{~nm}$ \\
\hline$D_{i}$ & Thickness of undoped layer in Nano-HEMT & $80 \mathrm{~nm}$ \\
\hline$\Delta d=d_{d}+d_{i}$ & Correction factor & $170 \mathrm{~nm}$ \\
\hline$\Phi_{b}$ & Schottky barrier Height & 0.697 \\
\hline$M$ & Mobility & $900 \mathrm{~cm}^{2} / \mathrm{Vs}$ \\
\hline$E_{g}$ & Band gap energy of GaAs & $3.44 \mathrm{eV}$ \\
\hline$N_{V}$ & Density of state in valance band & $9 \times 10^{18} \mathrm{~cm}^{-3}$ \\
\hline$N_{c}$ & Density of state in conduction band & $4.7 \times 10^{17} \mathrm{~cm}^{-3}$ \\
\hline$\epsilon_{s}$ & Semiconductor Permittivity & $12.9 \times 8.85 \times 10^{-14} \mathrm{~F} / \mathrm{cm}$ \\
\hline$V_{p 2}$ & Pinch-off voltage in doped layer & $1.75 \mathrm{~V}$ \\
\hline$F$ & Operating Frequency & $1 \mathrm{GHz}$ \\
\hline$N$ & No. of conduction Electrons & $10^{18}$ \\
\hline$\alpha_{H}$ & Hooge's Parameter & $2 \times 10^{3}$ \\
\hline
\end{tabular}

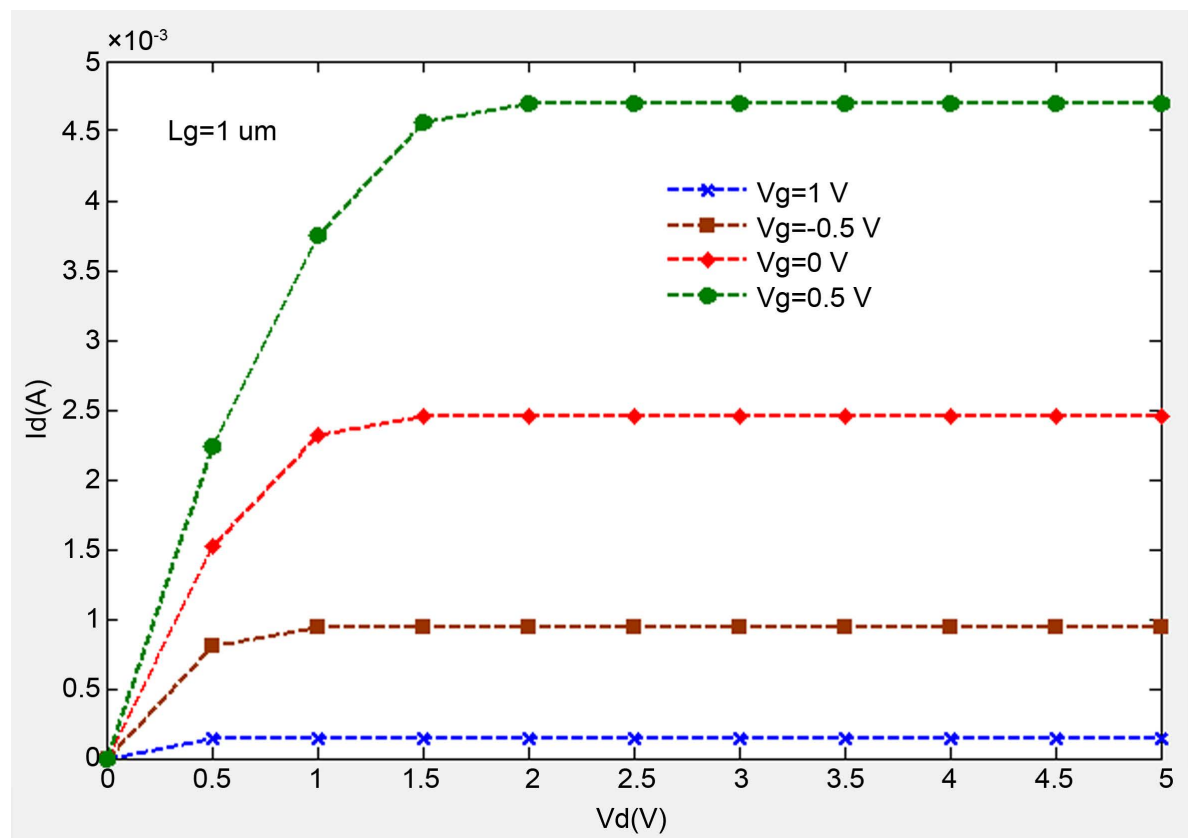

Figure 2. Id vs. Vd characteristics for $\mathrm{Lg}=1 \mathrm{um}, \mathrm{Vd}=(0 \mathrm{~V}$ to $5 \mathrm{~V})$ with step size $=0.5 \mathrm{~V}$ for various $\mathrm{Vg}$. 
Figure 4 and Figure 5 show the I-V characteristics for Micro and Nano GaN HEMT. In this case we have kept $\mathrm{Vd}$ as constant value and for the variation of $\mathrm{Vg}$. Even in this case if $\mathrm{Lg}=100 \mathrm{~nm}$ in Figure 5, the drain current is hundred times greater than the device which has $\mathrm{Lg}=1 \mathrm{um}$ in Figure 4. From the figures (Figures 2-5), it is observed that the drain current is higher for nanometer GaN HEMT with increasing gate voltage and/or drain voltage compare to micrometer GaN HEMT.

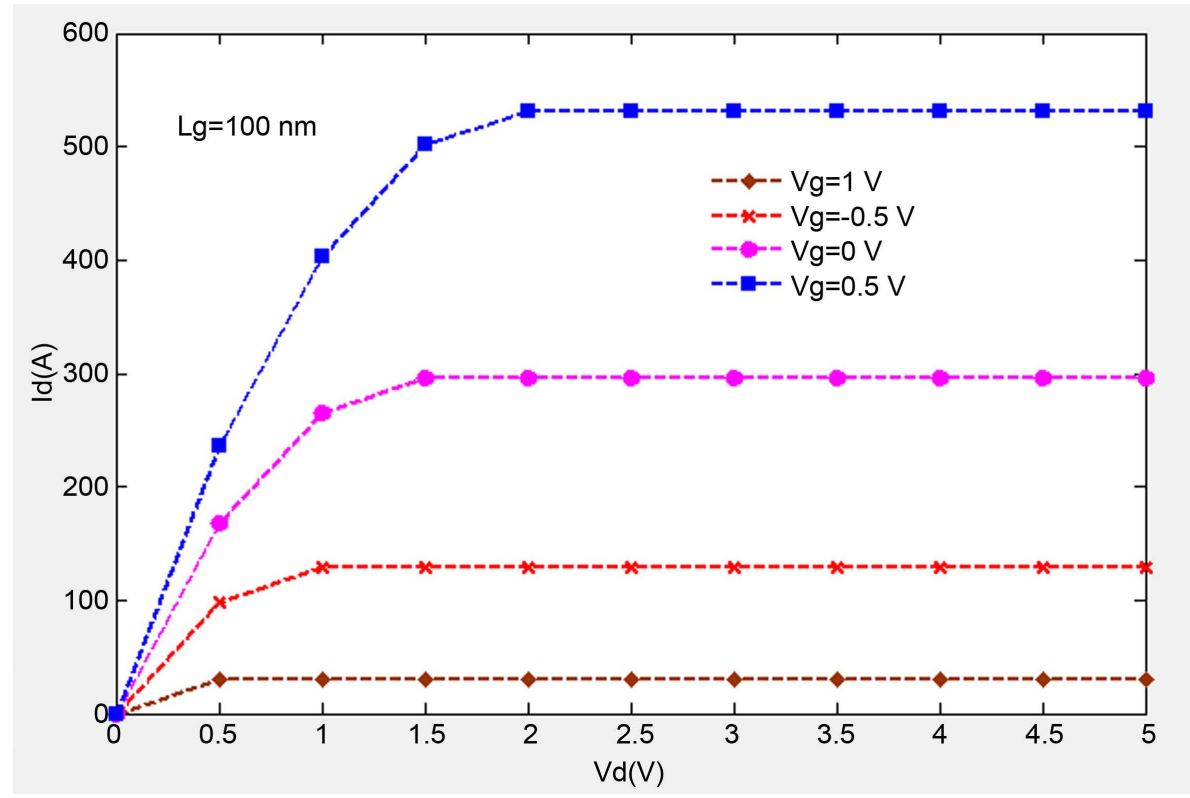

Figure 3. Id vs. Vd characteristics for $\mathrm{Lg}=100 \mathrm{~nm}, \mathrm{Vd}=(0 \mathrm{~V}$ to $5 \mathrm{~V})$ with step size $=0.5 \mathrm{~V}$ for various $\mathrm{Vg}$.

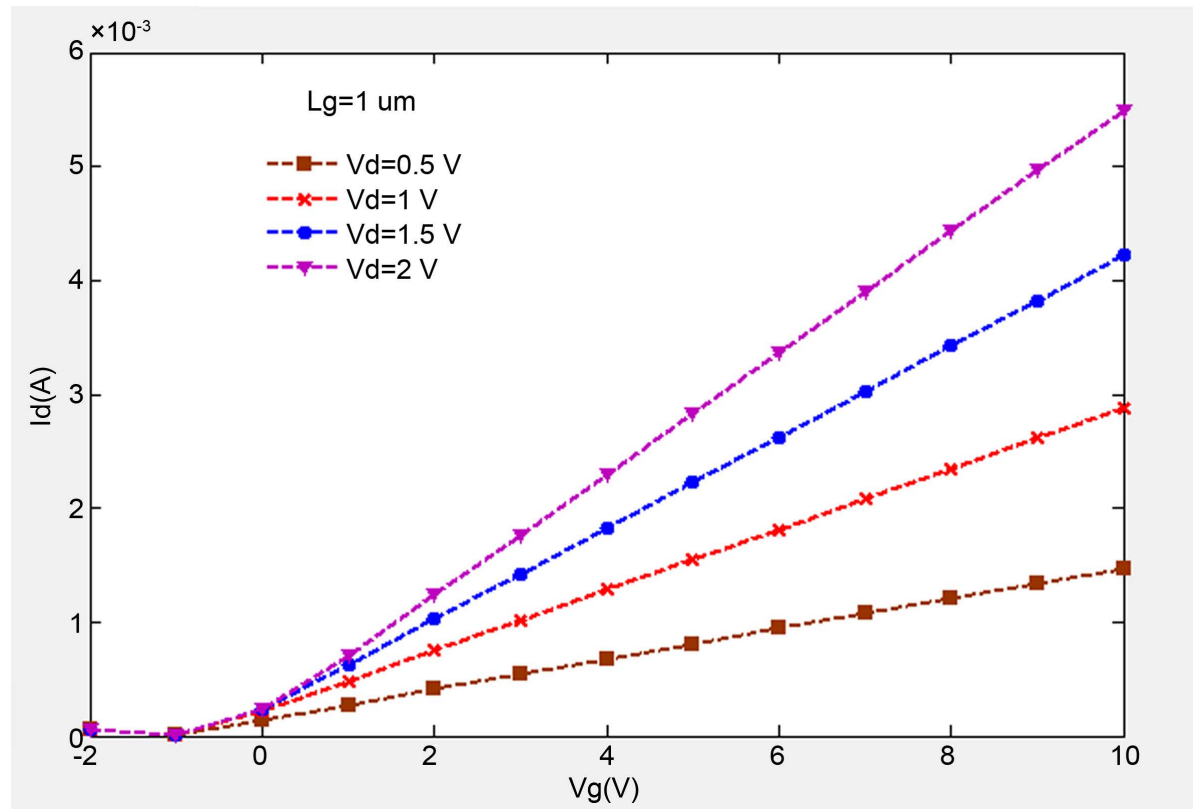

Figure 4. Id vs. $\mathrm{Vg}$ characteristics for $\mathrm{Lg}=1 \mathrm{um}, \mathrm{Vg}=(-2 \mathrm{~V}$ to $10 \mathrm{~V})$ with step size $=1 \mathrm{~V}$ for various $\mathrm{Vd}$. 
The nano GaN HEMT drain current characteristics are compared with the simulation results are shown in Figure 6 and Figure 7 for Id versus Vd and Id versus Vg respectively.

The noise generated inside this device is due to drain current fluctuation caused due to material or crystal defects in GaN HEMTs. This noise power spectral density analysis stresses on the power spectral density of noise due to the drain currents are analyzed in

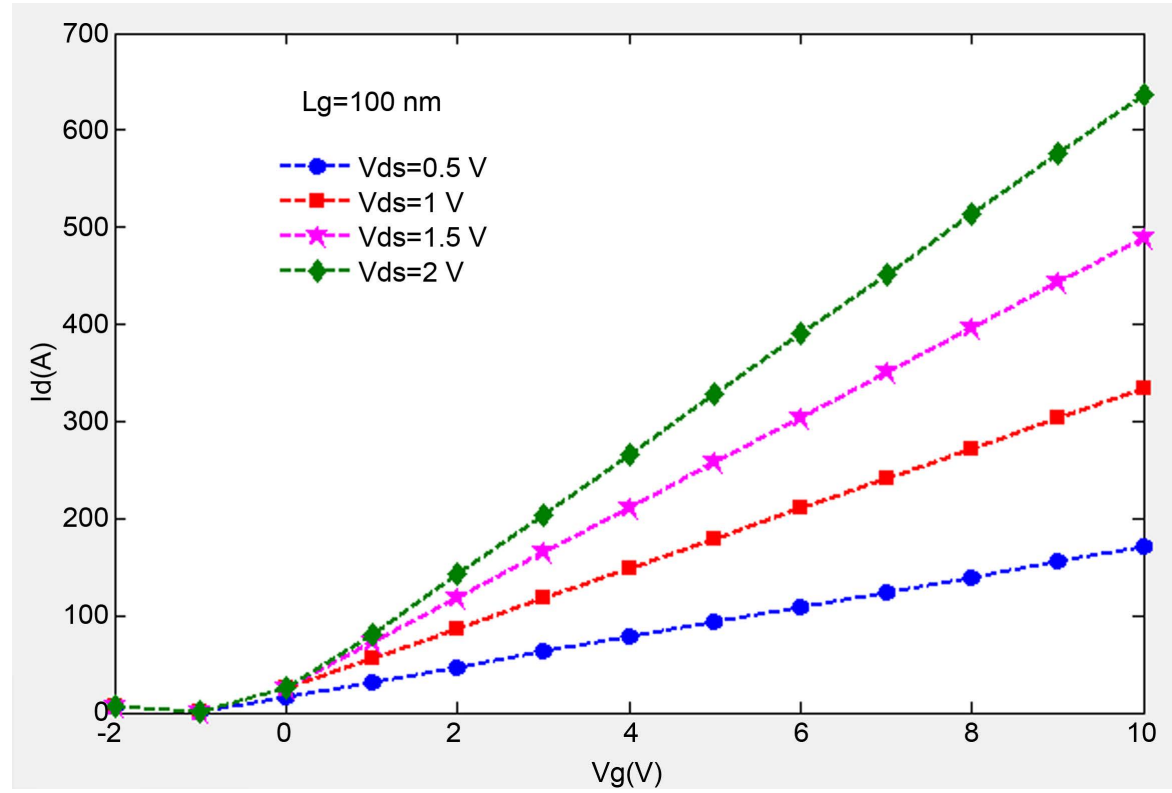

Figure 5. Id vs. Vg characteristics for $\mathrm{Lg}=100 \mathrm{~nm}, \mathrm{Vg}=(-2 \mathrm{~V}$ to $10 \mathrm{~V})$ with step size $=1 \mathrm{~V}$ for various $\mathrm{Vd}$.

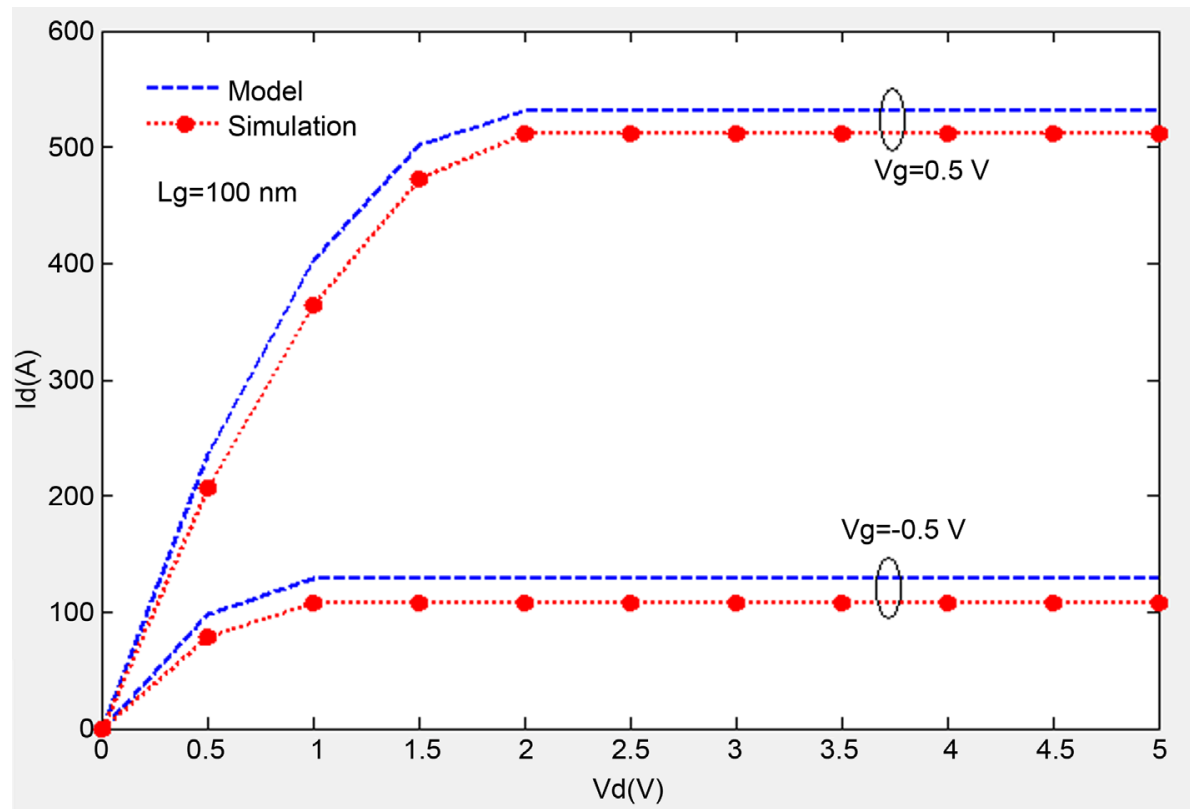

Figure 6. Model and simulation Id vs. Vd characteristics for $\mathrm{Lg}=100 \mathrm{~nm}$ for $\mathrm{Vg}=0.5 \mathrm{~V}$ and $-0.5 \mathrm{~V}$. 
Figure 8 and Figure 9.

The power spectral density (PSD) of the gate current noise shows a quadratic dependence on the gate current intensity. The noise PSD analysis on GaN HEMT comprises of plotting of noise PSD for different values of $\mathrm{Vg}$ from -1 to $0.5 \mathrm{~V}$, over a range of $\mathrm{Vd}$ from 0 to $5 \mathrm{~V}$ in Figure 8. Noise power spectrum density analysis of Nano HEMT using

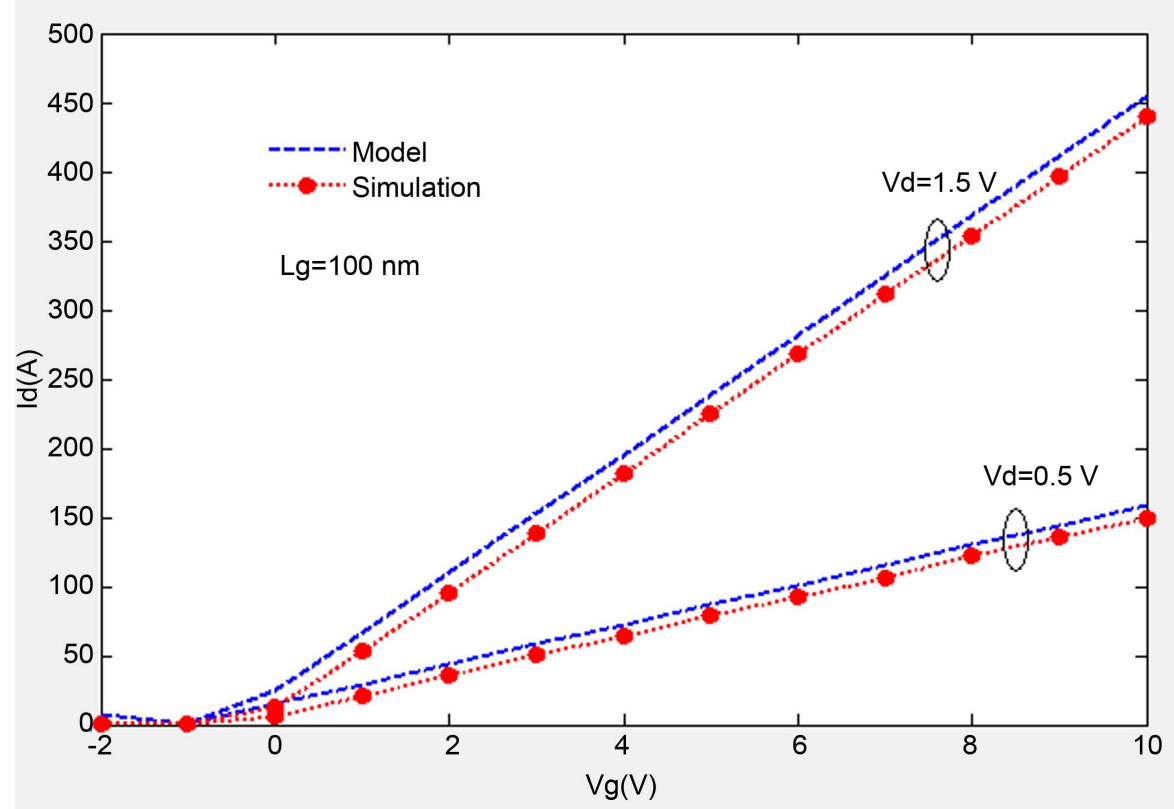

Figure 7. Model and simulation Id vs. Vg characteristics for $\mathrm{Lg}=100 \mathrm{~nm}$ for $\mathrm{Vd}=1.5 \mathrm{~V}$ and $0.5 \mathrm{~V}$.

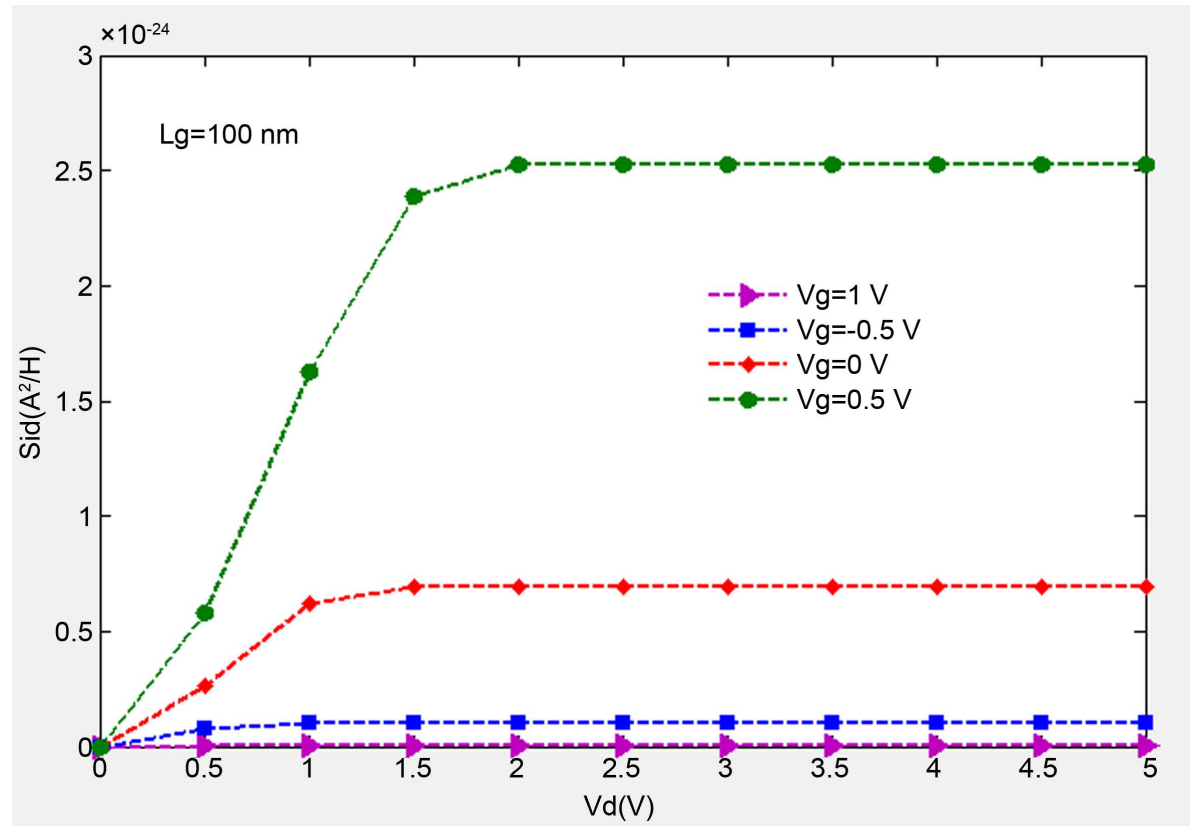

Figure 8. Vds-Sid characteristics of GaN nano HEMT with $\mathrm{Lg}=100 \mathrm{~nm}$ over $\mathrm{Vg}=-1 \mathrm{~V}$ to $0.5 \mathrm{~V}$. 
GaN material plotted with temperature is shown in Figure 9. Also the noise power spectral density model is compared with simulation results in Figure 10.

\section{Conclusion}

The model simulation for all the plots regarding Nano and Micro meter GaN HEMTs shows the comparative analysis for drain current characteristics. PSD analysis is done

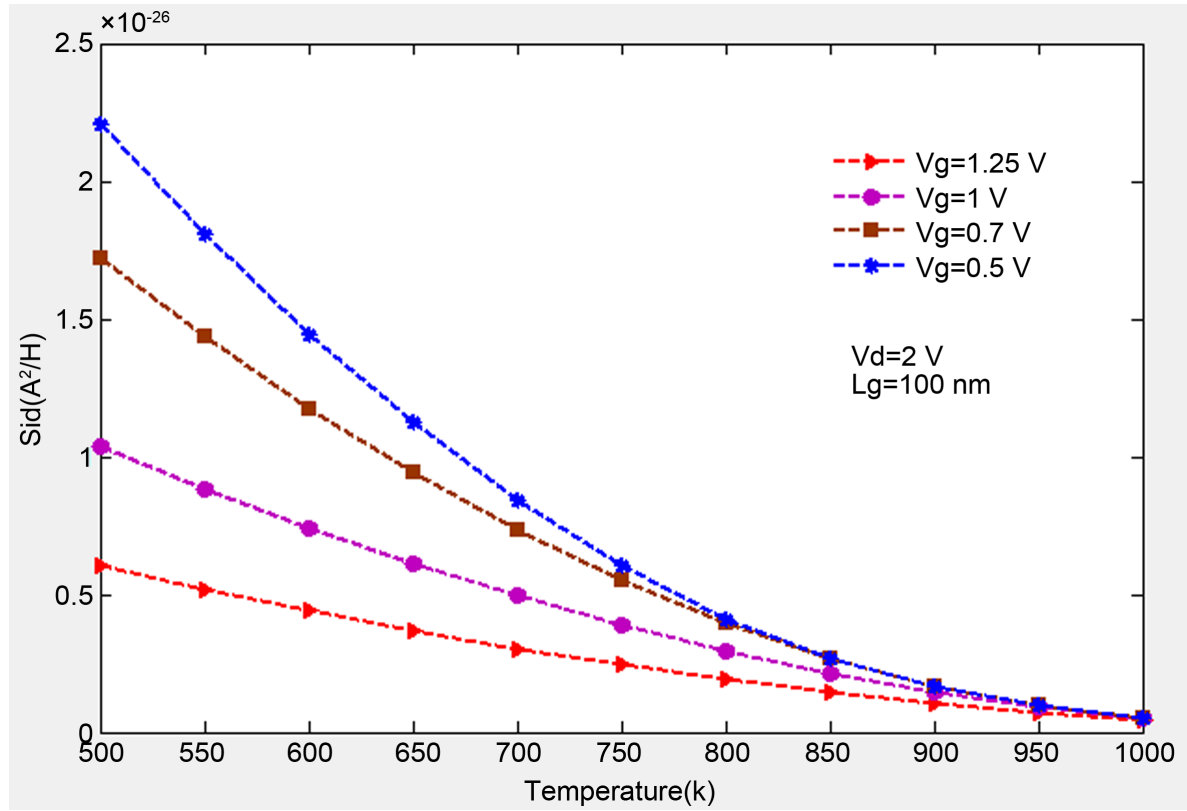

Figure 9. Temperature vs. Sid of GaN nano HEMT with $\mathrm{Lg}=100 \mathrm{~nm}$ for various gate voltage.

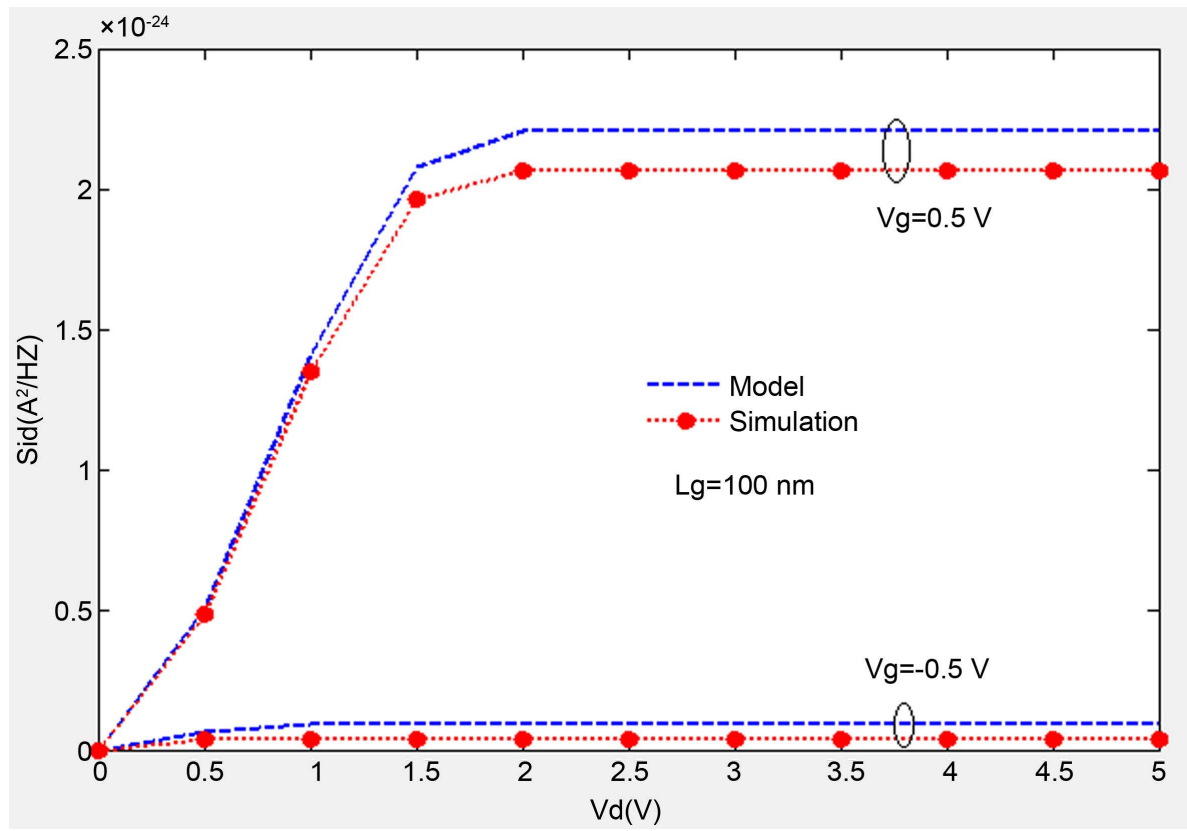

Figure 10. Model and simulation of Vds-Sid characteristics of GaN nano HEMT with $\mathrm{Lg}=$ $100 \mathrm{~nm}$ for $\mathrm{Vg}=0.5 \mathrm{~V}$ and $-0.5 \mathrm{~V}$. 
by considering reduced gate length in nanometer range of GaN HEMT. Also, it is observed that the amount of drain current generated by GaN Nano-HEMT is greater than normal GaN HEMT, but the former lacks in maintaining low noise PSD with higher frequency range, which is very poor as compared to GaN HEMT.

\section{References}

[1] Mishra, U.K., Parikh, P. and Wu, Y.F. (2002) AlGaN/GaN HEMTs-An Overview of Device Operation and Applications. Proceedings of the IEEE, 90, 1022-1031.

http://dx.doi.org/10.1109/JPROC.2002.1021567

[2] Khan, M.A., Bhattarai, A., Kuznia, J.N. and Olson, D.T. (1993) High Electron Mobility Transistors Based on a GaN/AlGaN Heterojunction. Applied Physics Letter, 63, 1214-1215. http://dx.doi.org/10.1063/1.109775

[3] Chen, C.-H., Keller, S., Haberer, E., Zhang, L.D., DenBaars, S.P., Hu, E.L., Mishra, U.K. and Wu, Y.F. (1999) Cl2 Reactive Ion Etching for Gate Recessing of AlGaN/GaN Field-Effect Transistors. Journal of Vacuum Science \& Technology B: Microelectronics Processing, 17, 2755-2758. http://dx.doi.org/10.1116/1.591058

[4] Cai, Y., Zhou, Y.G., Chen, K.J. and Lau, K.M. (2005) High-Performance EnhancementMode AlGaN/GaN HEMTs Using Fluoride-Based Plasma Treatment. IEEE Electron Device Letters, 26, 435-437. http://dx.doi.org/10.1109/LED.2005.851122

[5] Chang, C.Y., Pearton, S.J., Lo, C.F., Ren, F., Kravchenko, I.I.M., Dabiran, A., Wowchak, A.M., Cui, B. and Chow, P.P. (2009) Development of Enhancement Mode AlN/GaN High Electron Mobility Transistors. Applied Physics Letters, 94, Article ID: 263505. http://dx.doi.org/10.1063/1.3168648

[6] Uemoto, Y., Hikita, M., Ueno, H., Matsuo, H., Ishida, H., Yanagihara, M., Ueda, T., Tanaka, T. and Ueda, D. (2007) Gate Injection Transistor (GIT) - A Normally-Off AlGaN/GaN Power Transistor Using Conductivity Modulation. IEEE Transactions on Electron Devices, 54, 3393-3399. http://dx.doi.org/10.1109/TED.2007.908601

[7] Kuroda, M., Ueda, T. and Tanaka, T. (2010) Nonpolar AlGaN/GaN Metalinsulator-Semiconductor Heterojunction Field-Effect Transistors with a Normally-Off Operation. IEEE Transactions on Electron Devices, 57, 368-372. http://dx.doi.org/10.1109/TED.2009.2037458

[8] Ghaffari, M. and Orouji, A.A. (2015) Operational Improvement of AlGaN/GaN HEMT on SiC Substrate with the Amended Depletion Region. Physica E: Low-Dimensional Systems and Nanostructures, 74, 303-309. http://dx.doi.org/10.1016/j.physe.2015.07.016

[9] Aamir Ahsan, S., Ghosh, S., Sharma, K., Dasgupta, A., Khandelwal, S. and Chauhan, Y.S. (2016) Capacitance Modeling in Dual Field-Plate Power GaN HEMT for Accurate Switching Behavior. IEEE Transactions on Electron Devices, 63, 565-572. http://dx.doi.org/10.1109/TED.2015.2504726

[10] Levinshtein, M.E. (2000) Investigation of Low Frequency Noise Properties of Wide Gap Semiconductors, SiC and GaAs, And the Main Properties of the SiC Based Power Devices, Diodes and Thyristors. Technical Report, European Research Office of the US Army, London.

[11] Von Haartman, M. (2006) Low-Frequency Noise Characterization, Evaluation and Modeling of Advanced Si- and SiGe-Based CMOS Transistors. PhD Thesis, University in Stockholm, Sweden. 
Submit or recommend next manuscript to SCIRP and we will provide best service for you:

Accepting pre-submission inquiries through Email, Facebook, LinkedIn, Twitter, etc. A wide selection of journals (inclusive of 9 subjects, more than 200 journals)

Providing 24-hour high-quality service

User-friendly online submission system

Fair and swift peer-review system

Efficient typesetting and proofreading procedure

Display of the result of downloads and visits, as well as the number of cited articles

Maximum dissemination of your research work

Submit your manuscript at: http://papersubmission.scirp.org/

Or contact jamp@scirp.org 